\title{
O "BELO RISCO" DO ENSINO DE HISTÓRIA FRENTE AOS MEDOS DO MOVIMENTO ESCOLA SEM PARTIDO
}

\section{THE “BEAUTIFUL RISK” OF THE HISTORY TEACHING FACE THE FEARS OF THE ESCOLA SEM PARTIDO MOVEMENT}

\author{
João Carlos Escosteguy Filho ${ }^{1}$
}

\section{RESUMO}

O Movimento Escola sem Partido (MESP) tem se constituído em um dos principais espaços de concentração de ações, políticas e reflexões da "onda conservadora" para pensar educação e ensino de história no Brasil. Este artigo tece algumas reflexões e análises sobre uma obra fundamental para compreensão das concepções educacionais presentes no MESP: o livro Maquiavel Pedagogo, de Pascal Bernardin. Pretende-se, a partir da discussão de alguns pontos essenciais do livro, encaminhar uma reflexão, ainda bastante provisória e inicial, a respeito de como o ensino de história pode responder à ameaça representada pelo MESP, especialmente no que se refere à interdição proposta pelos apoiadores desse movimento para o lugar da política e do questionamento radical dentro do ensino da disciplina.

\section{PALAVRAS-CHAVE}

Escola sem Partido; Maquiavel Pedagogo; Ensino de História.

\begin{abstract}
The Escola Sem Partido Movement (MESP) has been one of the main spaces for the $x$ 'the discussions about education and history teaching in Brazil. This article aims to make some reflections and analyzes on a fundamental book for understanding the educational concepts present in MESP: its title is Maquiavel Pedagogo, by Pascal Bernardin. Based on the discussion of some essential points of the book, it is intended to lead a reflection, still very provisional and initial, on how history teaching can respond to the threat posed by MESP, especially with regard to the interdiction proposed by supporters of this movement to the place of politics and radical questioning within the teaching of the discipline.
\end{abstract}

\section{KEYWORDS}

Escola sem Partido, Maquiavel Pedagogo, History Teaching.

\footnotetext{
${ }^{1}$ Doutor em História pela UFF (2016). Professor do Instituto Federal de Educação, Ciência e Tecnologia do Rio de Janeiro - IFRJ. Docente dos cursos técnicos integrados ao nível médio e da Pós-Graduação em Educação em Direitos Humanos do Campus Pinheiral.
} 


\section{Introdução}

Surgido em 2004, o Movimento Escola sem Partido (MESP) não recebeu, de início, importância à altura de sua ameaça. A partir do momento em que projetos de lei inspirados no movimento começam a alcançar mais ampla difusão pelo território nacional, contudo, passaram a acumular-se estudos sobre o fenômeno, indo dos mais ensaísticos aos de mais sólida base empírica, discutindo desde as concepções educacionais presentes, de modo mais ou menos explícito, nas atuações do MESP, até suas redes de apoio, seus projetos de lei e sua contextualização em movimentos semelhantes ao longo do tempo. ${ }^{2}$

Um aspecto proporcionalmente menos tratado, porém, diz respeito a autores e/ou livros que dão sustentação conceitual ao MESP. Dentre as exceções encontram-se os trabalhos de Diogo Salles e Fernando Penna, que analisaram brevemente autores como Olavo de Carvalho (PENNA; SALLES, 2017) e obras como "Professor não é educador" (PENNA, 2016a), que balizam muitos dos sentidos educacionais do MESP. Salles (2019) ainda se dedicou mais profundamente ao trabalho de Nelson Lehmann da Silva. Em comum, todos esses autores analisados produziram suas concepções antes do início do MESP, servindo de norte para o movimento tanto no que diz respeito aos métodos quanto às concepções de "atuação docente" e "doutrinação", centrais para seu projeto educacional.

Uma obra, entretanto, ainda foi pouco considerada nas análises sobre concepções que sustentam a lógica do MESP. Refiro-me ao livro Maquiavel Pedagogo, de Pascal Bernardin (2013). Ausente nas referências diretas da "Biblioteca Politicamente Incorreta" do website do Escola sem Partido, o referido livro está presente, porém, de forma difusa nos mais diversos espaços que compõem o MESP, seja por indicações diretas, seja por referências indiretas aos termos e perspectivas que dão dimensão global àquilo que é proposto pelo MESP. Dessa maneira, aprofundar a discussão a partir do livro pode nos auxiliar a compreender não apenas as lógicas que sustentam o MESP de maneira mais

\footnotetext{
${ }^{2}$ Não cabe aqui uma reconstituição mais aprofundada da trajetória do MESP, já bastante presente na produção a seu respeito. Para abordagens mais gerais do movimento, são essenciais as obras coletivas organizadas pela AÇÃO EDUCATIVA (2016) e por FRIGOTO (2017).
} 
ampla, mas também, principalmente, os motivos pelos quais o ensino de humanidades, de modo mais geral, e particularmente o ensino de história, constituem alvos preferenciais do MESP. ${ }^{3}$

Este artigo tem como principal objetivo, portanto, analisar a referida obra, centrando-se, especialmente em duas dimensões: 1) as questões, temáticas, proposições e concepções de mundo que o livro e os arautos do MESP partilham; 2) as ameaças das concepções presentes em Maquiavel Pedagogo para o ensino de história. Para tanto, o texto será dividido em duas partes, além desta introdução e das considerações finais. $\mathrm{Na}$ primeira, justificarei com mais vagar a importância de Maquiavel Pedagogo para a compreensão do discurso do MESP a partir da análise da presença desse livro em falas de personagens centrais do movimento. Na segunda, o foco será a obra em si. Por fim, nas considerações finais, lançarei brevemente alguns apontamentos sobre o papel do ensino de história frente às ameaças presentes na referida obra.

Sugiro que não basta combater a ofensiva conservadora ${ }^{4}$ a partir somente da defesa do ensino de história em abstrato como promotor de uma visão racionalista de mundo. Ao invés, considero essencial que esse ensino esteja profundamente comprometido com aquilo que o MESP rejeita e busca tirar da sala de aula: uma educação política e emancipatória que, posicionando-se contra a lógica da aprendizagem, se direcione com energia para uma concepção conflituosa de democracia e para a "violação à soberania do estudante" (BIESTA, 2013, p. 47-49). Ao arrepio das propostas de

\footnotetext{
${ }^{3}$ A maior parte dos trabalhos sobre o MESP tem centrado sua análise nas ameaças à educação democrática/emancipadora de forma mais geral, ou nos ataques às discussões de gênero a partir, principalmente, da iniciativa fundamentalista cristã sobre os projetos de lei inspirados no movimento. Estou de acordo, porém, com Luis Felipe Miguel quando afirma que o movimento religioso contra as questões de gênero "é inteiramente independente do Movimento Escola sem Partido", que, para o autor, inclusive, "nasceu com outra agenda" (2016, p. 599). Essa "outra agenda" refere-se precisamente à ideia de que há um imenso movimento de doutrinação marxista-comunista nas aulas de humanidades, especialmente no ensino de história no país, e foi em torno dessa questão, a partir de ataques do jornalista Ali Kamel a livros didáticos da disciplina, que o MESP teve seu "primeiro momento" de expansão pós surgimento, por volta de 2007-2008 (MOURA, 2016, p. 27). Assim, entendo que o MESP nasce intimamente relacionado ao ensino de história mais do que a questões de gênero, bandeira a que só se agregará mais profundamente o movimento a partir do "segundo momento" de expansão do Escola sem Partido, associado ao levante contra o Ministério da Educação a partir do que ficou pejorativamente conhecido como "kit gay", em 2011-2012, e, mais ainda, do "terceiro momento", identificado com o impeachment da presidenta Dilma Rousseff, em 2015-2016. Nesse terceiro momento, já explodiam projetos de lei visando à implementação das diretrizes do MESP tanto no âmbito nacional quanto nos estaduais e municipais pelo Brasil (Idem).

${ }^{4}$ Por razões estilísticas, utilizarei apenas o termo "conservadora" para me referir à onda que, nos últimos anos, ascendeu com força no país, embora considere que uma melhor compreensão do fenômeno precisa situá-lo num bloco liberal-conservador-reacionário que congrega mais segmentos das forças políticas opositoras ao campo progressista.
} 
Maquiavel Pedagogo, endossadas e ressoadas pelo MESP, acredito que seja aí que podemos encontrar, parafraseando Gert Biesta, um "belo risco" para o ensino de história.

\section{Maquiavel Pedagogo nos discursos do MESP}

Publicado originalmente em 1995, em língua francesa, Maquiavel Pedagogo foi escrito pelo jornalista, engenheiro e professor francês Pascal Bernardin. Segundo o site da Vide Editorial, que publicou o livro no Brasil em 2013, Bernardin ministra aulas de ciências da computação na Universidade de Aix-Marseille III e escreve para a revista Lectures artigos focados nas temáticas de educação, meio ambiente, política internacional e globalismo. ${ }^{5}$

Fica evidente de cara como a teia temática preferencial de Bernardin forma uma totalidade que está na ordem do dia de boa parte da onda conservadora em ascensão no país. Para além da questão educacional, nosso foco principal, Bernardin tem um segundo livro traduzido no Brasil (2015) em que atribui à discussão ecológica contemporânea um caráter de busca pela criação de um governo mundial totalitário. Ou seja, as preocupações ambientais do último século seriam apenas pretexto para a ressurreição de ideais comunistas de dominação mundial, uma verdadeira ameaça às soberanias nacionais e às liberdades, argumento muito próximo do que o autor desenvolve em Maquiavel Pedagogo (2013). Ao conectar as preocupações de educação ao meio ambiente, então, está o panorama da política mundial lido a partir do conceito de globalismo, que, de restrito a certos círculos da direita midiática, marcado quase sempre por um grande sentimento conspiratório, ascendeu a instrumento da política externa do país desde a eleição de Jair Bolsonaro e da ocupação do Itamaraty pelo ministro Ernesto Araújo - por sinal, discípulo de Olavo de Carvalho, um dos autores centrais para a compreensão do MESP, como argumentam Penna e Salles (2017). ${ }^{6}$

\footnotetext{
5 https://videeditorial.com.br/index.php?route=product/author\&author_id=1214. Última visita em 01/04/2020.

${ }^{6}$ Já em seu discurso de posse, Ernesto Araújo (2019) mencionou oito vezes o termo "globalismo". Para o ministro, o Brasil tinha sua trajetória na política externa marcada pela busca por ser "bom aluno na escola do globalismo". Considera que um de seus esforços deve dirigir-se para "lutar para reverter o globalismo e empurrá-lo de volta ao seu ponto de partida". E, ainda, sintetiza: "O globalismo se constitui no ódio, através das suas várias ramificações ideológicas e seus instrumentos contrários à nação, contrários à natureza humana, e contrários ao próprio nascimento humano." Como sói ocorrer com os termos e conceitos
} 
Ambos os livros de Bernardin no Brasil foram publicados pela Vide Editorial, selo do Centro de Desenvolvimento Profissional e Tecnológico Ltda (CEDET) ${ }^{7}$. Surgida em 2009, a Vide Editorial notabilizou-se pela publicação massiva de obras que auxiliaram na construção de concepções de mundo da onda conservadora. Em seu catálogo constam autores e obras fundamentais para a construção ideológica dos três pilares que Luis Felipe Miguel aponta como constituintes da conjugação que resultou nos discursos reacionários no Brasil recente: o libertarianismo, o fundamentalismo religioso e o anticomunismo (MIGUEL, 2016, p. 592). Dentre os autores publicados pela casa, um ganha destaque para nossos propósitos aqui: exatamente Olavo de Carvalho, que vem tendo sua obra publicada e vendida sistematicamente pela Vide.

Sigamos nessa aproximação. Em recente entrevista a Eduardo Bolsonaro, filho do presidente Jair Bolsonaro, Olavo de Carvalho foi presenteado pelo entrevistador exatamente com a obra Maquiavel Pedagogo. ${ }^{8}$ Em que pese a demonstração de surpresa que Olavo de Carvalho demonstrou ao receber o presente ${ }^{9}$, o livro indica que a "edição brasileira [foi] autorizada ao Instituto Olavo de Carvalho pelo autor." ${ }^{10}$ O próprio Olavo de Carvalho, em artigo originalmente publicado no Diário do Comércio, já afirmara: "recentemente a Vide Editorial publicou, a conselho meu, a obra-padrão sobre o assunto [falava de técnicas de manipulação comportamental]: Maquiavel Pedagogo ou $\mathrm{O}$ Ministério da Reforma Psicológica, de Pascal Bernardin.” (2013).

Não bastassem essas afinidades, restaria ainda o fato de que algumas das mais antigas referências à obra dentre autores brasileiros partiram de Olavo de Carvalho. Embora não haja menções ao livro nas obras centrais que publicou nos anos 90 (2015;

utilizados por essa direita midiática de alguma forma próxima do MESP, inexiste na fala do ministro, qualquer proximidade com uma definição conceitual que possa embasar uma discussão mais complexa.

${ }^{7}$ O CEDET afirma, em seu site, ser empresa proprietária também de outros selos editoriais, como a Ecclesiae, cuja linha editorial existe "em consonância com a tradição da Igreja"; a Edições Livre, cujo foco principal são "livros católicos, literatura e clássico do pensamento ocidental", e, mais recentemente, o Kírion, "voltado para a área da educação". Também há o selo Auster, publicando no catálogo "biografias, humor e autoajuda". As informações constam em: https://www.cedet.com.br/editoras-proprias.php. Acesso em $01 / 04 / 2020$.

${ }^{8} \mathrm{O}$ programa de entrevistas conduzido por Eduardo Bolsonaro é intitulado "O Brasil Precisa Saber". É apresentado no Youtube. A entrevista com Olavo de Carvalho pode ser encontrada em: https://www.youtube.com/watch?v=9w3PYUYQNzw. Acesso em 01/04/2020.

${ }^{9}$ Carvalho afirma, aparentando surpresa, a partir de 22:12: "oh, vocês publicaram isso [Maquiavel Pedagogo] no Brasil?"

${ }^{10}$ Embora aparentemente seja uma instituição à parte de Olavo de Carvalho, o instituto que leva seu nome, com sede em Curitiba, parece suficientemente próximo pessoalmente de Carvalho para que seja divulgado em seu site: http://old.olavodecarvalho.org/avisos/institutoodec.html. 
2018), Carvalho já divulgava Maquiavel Pedagogo como obra de referência para se pensar o que concebia como o grande risco à educação escolar desde pelo menos 1999 apenas quatro anos após a publicação original do livro, e cinco antes de o ESP surgir. ${ }^{11}$ Entre 2000 e 2015 (isto é, desde antes do surgimento do Escola sem Partido até o alvorecer do "terceiro momento" do MESP), Olavo de Carvalho publicou ao menos mais 12 artigos com referências a Maquiavel Pedagogo nos mais diversos veículos, como os jornais O Globo, Zero Hora, Jornal da Tarde, Diário do Comércio e Jornal do Brasil. ${ }^{12}$ Ao longo desse período, dada a crescente influência de Carvalho junto a grupos da onda conservadora, de que o MESP faz parte, não é de surpreender que o livro comece a ser referenciado por cada vez mais grupos e pessoas.

Não é de nosso interesse para este artigo traçar um inventário de citações do livro de Bernardin. ${ }^{13}$ Considerando, contudo, essa presença difusa de Maquiavel Pedagogo, reafirmamos a necessidade de mais análises que contemplem a obra como parte essencial da construção das concepções do MESP. ${ }^{14}$

Inclusive porque podemos identificar a presença de Maquiavel Pedagogo no próprio fundador do ESP, Miguel Nagib. Em artigo (2013) publicado no site do ESP em 20 de dezembro de 2013, às vésperas do início da profusão dos projetos pelo país - o

\footnotetext{
${ }^{11}$ Essa mais antiga referência encontrada está presente em uma tradução, feita pelo próprio Olavo, de texto de Charles Lagrave a respeito do livro de Bernardin sobre o "Império Ecológico". O autor sintetiza (apud CARVALHO, 1999): "Na sua obra anterior, Machiavel pédagogue, o autor [Pascal Bernardin], apoiado em enorme massa de documentos oficiais, trazia-nos a prova de que um gigantesco empreendimento de lavagem cerebral vem se realizando no ensino, desde várias décadas, por meio das técnicas mais elaboradas de persuasão psicológica oculta (...). A subversão pedagógica tem por objetivo modificar os valores, as atitudes e os comportamentos, proceder a uma revolução psicológica, ética e cultural. Para chegar a isso, utilizam-se técnicas de manipulação psicológica e sociológica”. Vinte anos após a publicação do trecho destacado, a lógica interpretativa a ele associada alcançou os altos escalões da formulação de políticas públicas no país.

${ }^{12}$ Uma busca no website do autor (olavodecarvalho.org) com os termos Pascal Bernardin apontou esse resultado. Como não foi nosso objetivo estabelecer uma busca aprofundada, pode ser que haja mais textos ainda que façam referência à obra. Para além disso, uma busca nos demais espaços virtuais onde Olavo de Carvalho alcança audiência (Facebook, Youtube, Twitter etc.) revela muito mais referências à obra.

${ }^{13}$ A título de curiosidade, porém, podemos acompanhar algumas das pessoas, grupos e redes (ESPINOSA; QUEIROZ, 2017, p. 49-62) que compõem o MESP e que produziram interpretações e/ou difundiram o livro nos mais diversos meios estão: Rodrigo Constantino (2014), Ana Caroline Campagnolo (2013) - que inclusive publicou uma resenha em revista acadêmica sobre o livro (2013) -, jornalistas da Gazeta do Povo (como CASTRO, 2017) - que vem se notabilizando pela reunião de diversos intelectuais conservadores e articulistas divulgados pelo Instituto Liberal.(como CASTILHO, 2017) Além disso, o livro encontra uma profusão de vídeos e textos dentro do universo da direita midiática que ascendeu nos últimos anos, servindo também de referência para militantes da direita (CAMELO, 2019, p. 94).

${ }^{14}$ Uma exceção é ARAGUSUKU (2018, p. 71-72), que faz uma breve síntese das principais teses de Maquiavel Pedagogo ao analisar discurso do deputado Erivelton Santana, representante da Assembleia de Deus, que também analisaremos nesta seção.
} 
primeiro, lembramos, é de 2014 - e do "terceiro momento" do movimento, Nagib busca, em suas palavras, "desmentir a crença generalizada de que a educação sexual é um componente obrigatório do curriculum escolar". Seu texto visa a servir de embasamento para pais que porventura desejassem, ainda que apelando à Justiça, exercer "o direito, que lhes é assegurado pela Convenção Americana de Direitos Humanos, a que seus filhos recebam a educação moral que esteja de acordo com suas próprias convicções."15

Em certo momento do texto, Nagib estabelece uma distinção entre uma educação que "transmite conhecimento" e uma outra que busca "inculcar valores" (NABIG, 2013). Na crítica desta última, Nabig afirma:

\begin{abstract}
Nesse tipo de educação, o objetivo não é transmitir conhecimento, mas, sim, inculcar valores e sentimentos na consciência do estudante de modo que ele tenha determinado comportamento. É um tipo de lavagem cerebral, porque utiliza, muitas vezes, técnicas de manipulação mental bastantes [sic] conhecidas, conforme demonstrado por Pascal Bernardin, no livro "Maquiavel Pedagogo ou o ministério da reforma psicológica".
\end{abstract}

É constante no discurso de Nagib, nas mais diversas aparições públicas ou produções escritas, a separação entre público e privado na educação, ou entre a lógica familiar e a lógica escolar. A obra de Bernardin confere a essa distinção o sentido maior do perigo, já que, como melhor veremos na próxima seção deste artigo, todo o livro é construído sobre a suposição de que métodos de manipulação psicológica se têm espalhado pelo mundo sob aval das organizações "globalistas". E essas técnicas de manipulação, ao forçar alunas e alunos a ter comportamentos e atitudes distintas daquelas oriundas do seio familiar, acabam por produzir dissonâncias cognitivas que transformam as mentes ainda que imperceptivelmente.

A produção textual de Nagib, baseada em Maquiavel Pedagogo, já havia sido pronunciada quatro dias antes na Câmara dos Deputados, da boca do então deputado Erivelton Santana (PEN/BA), autor de um dos primeiros projetos de lei federal instituindo

\footnotetext{
${ }^{15}$ A argumentação do ESP no tocante ao uso seletivo da CADH, à abordagem do fenômeno educacional como mera relação contratual abraçada pelo direito do consumidor ou ao papel crescente que a discussão de gênero e sexual toma na lógica do MESP a partir especialmente do "segundo momento" indicado, tem sido já bastante analisada por diversos trabalhos (MIGUEL, 2016; MOURA, 2016; MOURA; SALLES, 2018, p. 136-160; MATTOS et. al., 2017, p. 87-104). Aqui nosso foco será o uso de Maquiavel Pedagogo.
} 
o Programa Escola sem Partido. ${ }^{16}$ Essa presença dupla, tanto na sociedade civil quanto na sociedade política (COLOMBO, 2018, p. 63), nos mostra que, para além da "dobradinha" que Moura (2016, p. 33) identifica entre ESP e proponentes das leis da mordaça, temos também uma afinidade conceitual em torno da obra de Bernardin. ${ }^{17}$

Considerando essa dupla presença e toda a justificação da abordagem de Maquiavel Pedagogo como componente de construção dessa visão de mundo consensual, passemos agora à análise do livro em si, buscando perceber de que maneira a interpretação lá traçada constitui não apenas um impedimento para qualquer abordagem minimamente cidadã, democrática ou emancipatória da educação, mas, essencialmente, constitui um golpe de morte em qualquer perspectiva do ensino de história que se pretenda algo mais do que a mera enumeração de fatos e personagens passados.

\title{
O maquiavelismo pedagógico dos globalistas
}

\begin{abstract}
Uma revolução pedagógica baseada nos resultados da pesquisa psicopedagógica está em curso no mundo inteiro. Ela é conduzida por especialistas em Ciências da Educação que, formados todos nos mesmos meios revolucionários, logo dominaram os departamentos de educação de diversas instituições internacionais: Unesco, Conselho da Europa, Comissão de Bruxelas e OCDE. (...) Essa revolução pedagógica visa a impor uma "ética voltada para a criação de uma nova sociedade" [nota] e a estabelecer uma sociedade intercultural. A nova ética não é outra coisa senão uma sofisticada reapresentação da utopia comunista. (BERNARDIN, 2013, p. 9-10)
\end{abstract}

As palavras que abrem a introdução já nos dão uma boa síntese do que pretende o autor. Estão presentes nesse trecho inicial as ideais centrais que serão posteriormente tratadas no livro: o mundo vem sendo tomado há décadas por um esforço de organizações mundiais globalistas voltado para uma profunda transformação nas mentes e atitudes dos alunos. O local privilegiado dessa revolução psicopedagógica é a sala de aula e seus

\footnotetext{
${ }^{16}$ Para ser mais preciso, o primeiro projeto declaradamente em busca da instituição do Programa Escola sem Partido é de 23 de março de 2015. Porém, quando apresentado, por ser muito similar ao PL 7180/14, este, sim, do deputado Erivelton, tramitou apensado a ele (MOURA, 2016, p. 32).

${ }^{17} \mathrm{O}$ trecho do discurso de Erivelton que remete a Maquiavel Pedagogo é uma absoluta paráfrase do artigo de Nagib, o que indica uma construção conjunta em torno da interpretação. Após criticar o uso das salas de aula como espaço para moldar juízos morais, sentimentos e atitudes dos estudantes em relação a certos temas, o deputado arremata: "Há quem denomine isso de educação de valores. (...) Por esse tipo de educação, o objetivo não é transmitir conhecimento aos alunos, mas sim inculcar determinados valores e sentimentos na consciência do estudante, a fim de que ele adote determinado comportamento. É um tipo de lavagem cerebral, porque utiliza, muitas vezes, técnicas de manipulação mental bastante conhecidas. Recomenda-se, a propósito, a leitura do livro Maquiavel Pedagogo, de Pascal Bernardin” (SANTANA, 2013).
} 
principais agentes são os professores. Nessa linha, as ações educativas empreendidas, voltadas para métodos de ensino-aprendizagem ativos, minariam os valores oriundos do seio familiar, ameaçando a própria constituição daquela que é considerada célula primordial das sociedades. Por fim, essa mentalidade revolucionária, que representa um perigo a ser evitado a todo custo, nada mais seria do que uma reatualização da utopia comunista, um "criptocomunismo" de que não se dão conta nem mesmo os principais agentes e as principais organizações que formulam essa ampla transformação. Apenas pessoas como Bernardin, Carvalho e Nagib perceberam o maquiavelismo dos globalistas.

Em que pese a tentação de restringir tal concepção de mundo a mera retórica conspiracionista, atirando-a imediatamente ao canteiro do pitoresco da história, devemos reafirmar a seriedade com que deve ser encarada essa concepção de mundo, que, num espaço de aproximadamente quinze anos, saiu das páginas de um obscuro livro francês para formulação de base de movimentos reacionários na sociedade civil e para política oficial de governo na sociedade política, tanto no Brasil quanto alhures.

Maquiavel Pedagogo é dividido em 14 capítulos, mais uma introdução, uma conclusão e uma "bibliografia seletiva" que, de tão seletiva, apresenta sugestão de apenas uma obra, considerada pelo autor um livro "capital, que nos abriu os olhos sobre a revolução do sistema educacional americano e ao qual nós devemos muito". ${ }^{18}$ Embora os capítulos não estejam agrupados em seções maiores, podemos dividir a obra em três blocos principais: o primeiro trata da ascensão, consolidação e difusão aquilo que o autor considera ser o conjunto de técnicas de manipulação psicológica que, uma vez alcançando o conjunto das entidades globalistas (ONU, Unesco, OCDE...), transformou-se no grande paradigma a pautar a revolução pedagógica planetária; o segundo bloco destrincha os significados e conteúdos da proposta pedagógica formulada por essas entidades e ameaçadora dos valores familiares; por fim, os capítulos finais retomam a discussão buscando a aplicabilidade do fenômeno na Europa, especialmente França, e nos Estados Unidos.

\footnotetext{
${ }^{18}$ Trata-se de EAKMAN, 1991. A restrição bibliográfica apresenta ainda dois problemas. O primeiro: apesar de ser chamada de "obra capital", há, em Maquiavel Pedagogo, apenas uma referência direta a ela: a nota 130, e num momento que não apresenta centralidade na argumentação. O segundo: a obra é referenciada com dois nomes distintos. Na nota 130, é chamada de Educating for the New Word Order (o nome correto); na bibliografia aparece como Education for the New World Order. Ressalte-se que pode ser simplesmente erro da edição brasileira, já que não comparamos com a original.
} 
Nos interessam especialmente os primeiros dois blocos, pois neles está contida a lógica de ataques mais próxima da utilizada pelo MESP. Tal lógica pode basicamente ser dividida em duas etapas, a partir da citação da introdução apontada acima: 1) construção de mecanismos de transformação de valores e atitudes dos alunos; 2) expansão dos ataques, a partir desses mecanismos, aos sentidos "verdadeiros" de educação, substituindo-os pela educação revolucionária que visa à implementação do comunismo.

A construção dos mecanismos componentes da revolução pedagógica teria entre seus traços mais importantes a "asfixia ou subordinação do ensino livre" e a "pretensão a anular a influência da família". Para tal, "os ensinos formal e intelectual são negligenciados em proveito de um ensino não cognitivo e multidimensional, privilegiando o social”. Isso justificaria, na visão do autor, o contínuo decaimento do nível escolar, "o que aliás não surpreende, já que o papel da escola foi redefinido e que sua missão principal não consiste mais na formação intelectual, e sim na formação social das crianças". A escola, assim, já não buscaria "fornecer a elas ferramentas para a autonomia intelectual, mas antes se lhes deseja impor, sub-repticiamente, valores, atitudes e comportamentos por meio de técnicas de manipulação psicológica." A isso Bernardin chama "ditadura psicopedagógica." (2013, p. 10-12).

O movimento de revolução pedagógica não apenas ameaçaria os valores familiares e a liberdade individual, mas também produziria uma profunda destruição da educação de qualidade, já que redefiniria a principal missão da escola, de formação intelectual. Para Bernardin, essa redefinição da missão escolar ainda estaria atrelada a uma nova faceta do comunismo, nascida "nos meios revolucionários norte-americanos, retomados e desenvolvidos ulteriormente pela URSS e pela Unesco". E como que antecipando uma contestação possível, munida de evidências, de que órgãos como a Unesco ou a OCDE pouco têm de comunistas, o autor já se adiantaria (2013, p. 13): "nos encontramos face a uma temível manobra criptocomunista, [que] não exclui, em absoluto, a hipótese globalista da convergência entre capitalismo e comunismo. (...) na verdade supõe a presença de um forte elemento criptocomunista na sociedade posterior à desaparição da cortina de ferro."

Em outras palavras, a presença comunista em organismos em tese do mundo capitalista se explicaria pelo globalismo. E não adiantaria afirmar que isso pouco diz. Em todo o livro, isso o mais próximo a que se chega de uma definição. O globalismo é 
entendido como uma espécie de aproximação entre comunismo e capitalismo, produzindo um amálgama sob predomínio do primeiro. Esse amálgama, que teria no trabalho para a “destruição ou para a subversão da fé" o seu “objetivo maior" (2013, p. 130), embora não tenha ainda convertido todas as elites, de acordo com o autor, caminharia rumo a uma transformação das distinções entre esquerda e direita que acabaria por transformar o próprio capitalismo em uma espécie de cavalo de Troia do comunismo - não tanto mais voltado à vitória sobre o capital, mas, sim, direcionado para a destruição da tradição por meio, inclusive, da educação multicultural (2013, p. 69-70).

O método da revolução seria o psicológico, e então Bernardin passa os capítulos seguintes expondo as técnicas desenvolvidas, a partir dos anos 1950, com o intuito de produzir mudanças comportamentais que independeriam da vontade do sujeito. Dentre todas as teorias e experiências psicológicas apresentadas, a mais importante para nossa argumentação é a da “dissonância cognitiva", elaborada em 1957 pelo psicólogo estadunidense Leon Festinger. Segundo Bernardin, "uma dissonância cognitiva é uma contradição entre dois elementos do psiquismo de um indivíduo, sejam eles: valor, sentimento, opinião, recordação de um ato, conhecimento etc", cujo estudo "permite perceber o quanto nossos atos podem influenciar nossas atitudes, crenças, valores ou opiniões." Afinal, ainda segundo o livro, "se é evidente que nossos atos, em medida mais ou menos vasta, são determinados por nossas opiniões, bem menos claro nos parece que o inverso seja verdadeiro, ou seja, que nossos atos possam modificar nossas opiniões." (2013, p. 23).

No entanto, argumenta Bernardin, é exatamente isso que ocorre, em especial "se um indivíduo é levado a cometer publicamente (na sala de aula, por exemplo) ou frequentemente (ao longo do curso) um ato em contradição com seus valores, sua tendência será a de modificar tais valores, para diminuir a tensão que lhe oprime.” Em outras palavras, quaisquer atitudes estimuladas em sala de aula, se aparecem em contradição com os valores que o estudante traz de casa, então o choque entre prática e pensamento faria com que aquela transformasse este, de modo que o resultado seria a completa transformação dos valores iniciais justamente naqueles que o planejamento escolar desejasse, resultando em uma profunda lavagem cerebral. Dessa maneira, qualquer proposição que leve a uma ação estudantil que contrarie seus valores constitui uma manipulação psicológica que visa somente a atacar os valores familiares. 
Quando adicionamos a isso o temor do conteúdo que transformará esses valores (aqueles globalistas hegemonizados pelo criptocomunismo), temos a maior parte do arsenal que o MESP tem disparado contra qualquer proposta de educação transformadora. Afinal, se ela busca transformar, tal se daria sempre por meio de uma profunda violência psicológica sobre os estudantes. Os professores, alvos a serem odiados, deveriam ser contidos o máximo possível se ousarem sugerir qualquer metodologia que contasse com participação ativa do corpo discente. Afinal, colocar o aluno frente a novas atitudes levaria necessariamente a um processo de racionalização que obrigaria o estudante a repensar seus valores, como forma de dar sentido à conexão entre pensamento e ação.

Tudo, para Bernardin, serviria de caminho para uma "revolução psicológica", composta por uma "revolução ética - a subversão dos valores" e por uma "revolução cultural". A única saída para impedir essa revolução promovida pelos agentes educadores seria, para o autor, desmontar os elementos constitutivos dessa "nova ética". Esses elementos, defendidos pelos globalistas e que deveriam ser profundamente atacados, são os seguintes:

\begin{abstract}
Os direitos humanos (estendidos ao direito social: direito à habitação, à alimentação, ao trabalho etc.); a bioética; os direitos das crianças (temível arma contra a família); a educação para a paz, a concórdia entre as nações, o desarmamento, o civismo pacífico, a fraternidade humana, a consciência da interdependência entre as nações (Unesco); a educação para o meio ambiente (Comissão de Bruxelas, Unesco); a criação de um "mundo mais justo e solidário, pilar da nova ordem internacional" (Parlamento Europeu); a "experiência da vida em uma sociedade multicultural" (Parlamento Europeu; temas similares na Comissão de Bruxelas e na Unesco); a tolerância (Unesco); a "passagem da competição à cooperação" (Unesco); o desenvolvimento da consciência política (Parlamento Europeu, Unesco); a "paz no espírito dos homens" (Unesco); etc. (BERNARDIN, 2013, p. 57-58)
\end{abstract}

Ainda que a disputa pela construção hegemônica de sentido para os termos em uso faça parte da luta política e ideológica, especialmente para aqueles que constituem “significantes vazios” (LACLAU, 2011, p. 67-80), não há qualquer possibilidade de considerar a citação acima uma simples disputa por significado para os termos elencados. Pelo contrário: a completa ausência desse tipo de reflexão em Maquiavel Pedagogo mostra que a simples presença dos termos em si já constitui imenso perigo, ainda que no sentido mais "moderado" possível, partindo de instituições transacionais comprometidas 
com os limites do próprio capitalismo. Assim, ao considerar a sugestão temática já uma transgressão revolucionária, Bernardin dirige sua crítica não a possíveis limitações dos sentidos dos termos, mas à mera presença deles na educação. Como resultado, podemos pensar, invertendo a proposição da referência, que, para o autor, uma lógica educacional válida só pode ser exercida pela violência, pela guerra, pela competição, pela homogeneização cultural e pelo descaso frente a qualquer concepção de Meio Ambiente e de Direitos Humanos.

Sob o argumento de que o método de promoção de valores éticos é questionável - ainda que, como admite o autor, seja feito em ambiente de troca, liberdade e de modo não-impositivo (na verdade, aí é que o método teria mais força...) - , Bernardin possibilita que o oposto das proposições constitua a norma social, abstendo-se de oferecer qualquer caminho para a superação das opressões, desigualdades, injustiças e violências do mundo em que vivemos. E a maior demonstração disso é que, logo após a enumeração dos itens indicados na citação acima, Bernardin assim analisa a passagem: "percebe-se aí, sob uma hábil apresentação, a retórica criptocomunista". (2013, p. 58).

E assim justifica o autor seu posicionamento crítico frente àquele conjunto de valores.

\begin{abstract}
a manobra destinada a modificar os valores articula-se assim: inicialmente, impedir a transmissão, especialmente por meio da família, dos valores tradicionais; face ao caos ético e social daí resultantes, torna-se imperativo o retorno a uma educação ética - controlada pelos Estados e pelas organizações internacionais, e não mais pela família. Pode-se, então, induzir e controlar a modificação dos valores. Esquema revolucionário clássico: tese, antítese e síntese, que explica a razão por que, chegada a hora, os revolucionários se fazem os defensores da ordem moral (BERNARDIN, 2013, p.66).
\end{abstract}

Sob o argumento de que aquele conjunto de valores constitui uma justificativa da revolução mundial contra a família, trava-se qualquer possibilidade de alteração social. O discurso em defesa da família, tão forte aqui como no MESP, é elevado a valor máximo social, sob o qual todos os demais se devem submeter, inclusive aqueles que combatam as mais variadas formas de violência social.

É claro que, frente a essa percepção do social, o ensino de história não poderia ficar de fora. Num capítulo convenientemente intitulado "reescrever a história", Bernardin (2013, p. 73) afirma que os objetivos anteriormente perseguidos pelas 
entidades globalistas (por exemplo: “educação para a paz”, "concordância entre nações”, "desarmamento", "fraternidade humana" e "experiência da vida em uma sociedade multicultural") não se poderiam satisfazer com o ensino da história tal como feito atualmente. Dessa forma, a busca pela eliminação dos conflitos entre nações, etnias ou religiões implicaria um projeto que exigiria, segundo Bernardin, "reescrever a história, projeto essencialmente totalitário." Essa reescrita totalitária da história consistiria basicamente na busca pelo ocultamento de "um de seus autênticos motores", isto é, na busca pela "mutilação psicológica, que deve amputar, das gerações futuras, as suas raízes", impossibilitando-lhes "toda a verdadeira compreensão política" (Idem).

O exemplo que Bernardin transcreve para ilustrar sua interpretação é da Unesco, propondo "a elaboração de um manual de história geral da Europa, bem como um manual de história universal, com a ativa participação de comitês de historiadores dos países interessados." O mesmo documento indica, ainda, a conveniência de se aperfeiçoar o ensino de história, bem como de outras ciências humanas, visando ao "despertar do interesse e a melhor compreensão de outras comunidades, a fim de impregnar tal interesse de um espírito de objetividade científica e de tolerância, eliminando tudo o que possa haver de desconfiança e de desprezo relativamente a outros povos.” Afinal, continua o texto (apud BERNARDIN, 2013, p. 73-74), "a simples apresentação objetiva dos fatos" seria "insuficiente para produzir a atitude desejada", devendo o ensino de história ser realizado "dentro de um verdadeiro espírito de tolerância, de modo a fazer compreender que os adversários de ontem são os parceiros de hoje, e que sua colaboração em uma obra comum só pode beneficiar a todos." Assim, "na medida em que se possa criar uma tal atmosfera, os temas relativos à paz, ao desarmamento, à cooperação e aos direitos humanos se impõem como uma obrigação."

Não está em questão aqui a eficácia da abordagem, ou mesmo a pertinência, de um ponto de vista epistemológico, da proposta da Unesco. Até porque não são esses os elementos da crítica de Bernardin. Nos interessa, muito mais, nesta reta final, atingir o ponto essencial da importância do ensino de história dentro dessa retórica. Afinal, o que Bernardin, bem como o MESP, desprezam no ensino da disciplina é justamente qualquer concepção que concorde com a ideia de que ela não deve se restringir à "apresentação objetiva dos fatos". Não apenas pela impossibilidade dessa abordagem - afinal, inexistem fatos sem interpretações a ele subjacentes, inclusive no recorte do que vem a constituir 
um fato histórico. Mas, principalmente, porque os sentidos do ensino de história estão sempre atrelados a concepções de mundo que veiculam valores, discutem política, escovam aspectos morais. Tudo, justamente, que Bernardin e o MESP recusam à área. Daí o autor afirmar, após a citação acima, o quanto "é revoltante a pouca importância que se dá à apresentação objetiva dos fatos" (2013, p. 74).

$\mathrm{Na}$ conclusão, retomando a discussão, Bernardin afirma: “o problema é, na verdade, mais vasto. Trata-se da aplicação das Ciências Humanas e Sociais à revolução, aplicação esta que não se limita apenas ao domínio do ensino.” (2013, p. 158).

Poderíamos nos perguntar, encaminhando nossas conclusões: pode um ensino minimamente significativo de história ser diferente?

\section{Considerações finais}

O pânico que compõe a base de sustentação da força do MESP frente à produção de leis e espalhamento do "ódio aos professores" (PENNA, 2016b), é sinteticamente descrito por Olavo de Carvalho (2009):

Só para vocês fazerem uma idéia de até onde a coisa chega, os programas educacionais de quase todas as nações do mundo, em vigor desde há pelo menos vinte anos, são determinados por normas homogêneas diretamente impostas pela ONU e calculadas não para desenvolver a inteligência ou a consciência moral das crianças, mas para fazer delas criaturas dóceis, facilmente amoldáveis, sem caráter, prontas a aderir entusiasticamente, sem discussão, a qualquer nova palavra-de-ordem que a elite global julgue útil aos seus objetivos. (...) Todas as disciplinas, incluindo matemática e ciências, foram remoldadas para servir a propósitos de manipulação psicológica. $\mathrm{O}$ próprio Pascal Bernardin descreveu meticulosamente o fenômeno em Machiavel Pédagogue (1995). Leia e descobrirá por que seu filho não consegue resolver uma equação de segundo grau ou completar uma frase sem três solecismos, mas volta da escola falando grosso como um comissário do povo, cobrando dos pais uma conduta "politicamente correta". (grifos meus)

O filho que volta da escola transformado em suas reflexões, não mais aceitando absurdos que porventura possam estar presentes em uma situação familiar, constitui o verdadeiro temor do MESP, e não a pura ausência de conteúdos mais básicos dos saberes disciplinares. Afinal, não há qualquer oposição entre a compreensão de conteúdos e a reflexão sobre os próprios valores. A falsa separação apontada serve apenas para que, a 
partir de certo senso comum sobre o que constitui a verdadeira educação, possa Carvalho - assim como o MESP - produzir uma clivagem na qual apenas uma das metades poderia ser tarefa escolar - justamente aquela que nada põe em cheque em termos de valores familiares.

Como pode o ensino de história se posicionar frente a essa questão? Podemos responder invertendo o sentido da crítica a partir de uma provocação: Pascal Bernardin e o MESP estão absolutamente corretos em um aspecto: o ensino de história mais significativo só pode, de fato, transformar de tal maneira o(a) aluno(a) que ele(a) romperia, ao menos em parte, com as concepções oriundas do núcleo familiar.

Explico a provocação com o auxílio de um autor que tem sido muito significativo para boa parte dos trabalhos que buscam explicar os problemas concernentes ao MESP: Gert Biesta.

Para Biesta (2012; 2010, n.p.), a educação compreende três dimensões que, não obstante se entrelacem, podem ser compreendidas separadamente. São elas a dimensão da qualificação, da socialização e da subjetivação. Nos interessa esta última em particular, para Biesta aquela que constitui o mais profundo sentido da educação, afastando-se de qualquer confusão entre "educação" e mera "aprendizagem".

A subjetivação tem esse papel central porque é nessa dimensão que se torna possível, pela educação, a ênfase no "vir ao mundo"; o foco em possibilitar que cada indivíduo possa ter sua unicidade, sua voz própria, e não há apenas a preocupação com conteúdos que possam formar sua base de compreensão da realidade, ou com processos de inserção num mundo já formado, respectivamente focos da qualificação e da socialização. Biesta deixa claro que não se trata de eliminar ou minimizar essas dimensões, mas de compreender que a educação é mais digna desse nome na medida em que cumpre as possibilidades da subjetivação. Essas possibilidades, quando ressaltadas no processo educativo, constituem uma "educação fraca" (BIESTA, 2016, n.p.) - isto é, incapazes de controlar com rigor os processos pelos quais os resultados atendem aos objetivos iniciais.

Nesse sentido, Biesta, baseado em Derrida, destaca o quanto esse processo se dá por meio de uma "violência transcendental", um tipo de violência que necessariamente viola a soberania do aluno (BIESTA, 2013, p. 46-50). Isso não significa que a educação deva ser bruta. Significa que "a educação é uma forma de violência, uma vez que interfere 
na soberania do sujeito propondo questões difíceis e criando encontros difíceis.” (2013, p. 49). Afinal, sem a disposição para ter suas certezas, convicções, valores desafiados, deslocados, redefinidos, torna-se impossível trazer o novo ao mundo. Restaria apenas a reiteração do velho, do mesmo. O novo surge sempre nos fragmentos dos processos da "educação forte", e é capaz de surgir mesmo sem uma dinâmica voltada para sua existência.

Nisto consiste, para o autor, o "belo risco da educação". A partir de W. B. Yeats, Biesta (2016, n.p.) destaca como, se a tônica, na educação, é trazer o "novo", é o "vir ao mundo", então não se trata de encher um balde, mas de acender uma fogueira; se trata de iniciar um processo cuja conclusão desconhecemos, mas que constitui, para o autor, a única possibilidade do irrompimento do "novo" na educação. Eis o "belo risco": o fato de que a educação abraça processos sobre os quais temos pouco controle, baseados em confiança sem fundamento e responsabilidade sobre o que não sabemos o que será. Tratase, em síntese, de um despertar cujas consequências não conseguimos de antemão delimitar. Apenas o processo pode nos dar perspectivas.

Tal dimensão educacional aproxima-se de certa concepção conflituosa de democracia que a compreende não como a busca pela construção do consenso que anula a disputa (afinal, impossível), mas como espaço no qual os conflitos fazem parte da própria vivência democrática (MOUFFE, 2015). Entender o "belo risco" inerente à educação - ou, mais especificamente para nossos termos, ao ensino de história - é compreender que seu compromisso com uma vivência democrática não pode se restringir a mero "conteudismo" que permitiria uma melhor qualificação para o exercício da cidadania (como se tal exercício fosse algo a ser alcançado no futuro, porém impossibilitado no presente), nem tampouco pode se restringir a certo racionalismo abstrato para o qual o simples conhecimento teórico da realidade pode dar conta de uma transformação da mesma.

Uma concepção que mais potencializa o ensino de história, explicitando todo o "belo risco" a ele inerente, só pode ser aquela que parte do questionamento radical de si e dos outros. Do questionamento só possível pela igualdade como princípio que emancipa, ao invés de brutalizar (RANCIÉRE, 2013, p.50). Do questionamento que invade de tal maneira o processo de ensino-aprendizagem que permite a "interrupção do ser de um ser" (BIESTA, 2013, p. 194); uma descontinuidade que, na lógica do MESP e 
de Bernardin, ameaça seriamente o controle familiar. E que deve, sim, neste sentido ao menos, ameaçar, do mesmo modo que o conceito de "emancipação" tem suas raízes na lei romana, referindo-se à libertação de um filho ou esposa da autoridade legal do pater famílias (BIESTA, 2016, n.p.). Uma educação emancipatória só pode significar a libertação da autoridade intelectual perante a família (bem como perante outras instâncias e espaços de poder, inclusive, por que não?, da própria escola...) rumo a uma mais plena autonomia só possibilitada pela permanente "curiosidade epistemológica" voltada à transformação de si e do mundo (FREIRE, 2011, n.p.).

O delineamento dessa proposta ultrapassaria os limites deste artigo, exigindo mais espaço de reflexão. Aqui, meu objetivo foi o de levantar alguns pontos iniciais para reflexão coletiva. Como um ensino aberto dentro de uma lógica "fraca", talvez possamos estar nos arriscando demais ao não ir além dessas considerações iniciais. Contudo, acredito que é nessa "fraqueza" que reside a necessária "força" para o enfrentamento que o MESP e seus formuladores exigem.

\section{REFERÊNCIAS}

AÇÃO EDUCATIVA (org.). A ideologia do movimento Escola sem Partido: 20 autores desmontam o discurso. São Paulo: Ação Educativa, 2016.

ARAGUSUKU, Henrique Araujo. O discurso da "ideologia de gênero" na Câmara dos Deputados: análise crítico-discursiva e psicopolítica. Dissertação (Mestrado em Ciências) - Instituto de Psicologia, Universidade de São Paulo, São Paulo, 2018.

ARAUJO, Ernesto. Discurso do ministro Ernesto Araújo durante cerimônia de Posse no Ministério das Relações Exteriores - Brasília, 2 de janeiro de 2019 [online] Disponível em: $<$ http://www.itamaraty.gov.br/pt-BR/discursos-artigos-e-entrevistas-categoria/ministrodas-relacoes-exteriores-discursos/19907-discurso-do-ministro-ernesto-araujo-durantecerimonia-de-posse-no-ministerio-das-relacoes-exteriores-brasilia-2-de-janeiro-de2019>. Acesso em 01 abril 2020.

BELLEI, Ana Caroline Campagnolo. Resenha da obra "Maquiavel Pedagogo ou o ministério da reforma psicológica", de Pascal Bernardin [online]. Disponível em: <https://www.revista.ueg.br/index.php/revistapluraisvirtual/article/view/2257>. 2013. Acesso em 01 abril 2020.

BERNARDIN, Pascal. Maquiavel Pedagogo: ou o ministério da reforma psicológica. Campinas, SP: Ecclesia e Vide Editorial, 2013. 
; O Império Ecológico: ou a subversão da ecologia pelo globalismo. Campinas, SP: Vide Editorial, 2015.

BIESTA, Gert. Boa educação na era da mensuração. Cadernos de Pesquisa, v. 42, n. 147, pp. 808-825, set-dez 2012.

Good Education in an Age of Measurement. [S.1.] Paradigm Publichers, 2010.

Para além da aprendizagem: educação democrática para um futuro humano. Belo Horizonte: Autêntica Editora, 2013a

The Beautiful Risk of Education. New York, NY: Routledge, 2016.

CAMELO, Edgar Antônio Nery Alves. O Programa "Escola sem Partido" em Goiânia: implicações e consequências para a educação pública. Dissertação (Mestrado em Sociologia) - Faculdade de Ciências Sociais, Universidade Federal de Goiás, Goiânia, 2019.

CAMPAGNOLO, Ana Caroline. VLOGOTECA - Maquiavel Pedagogo: ou o ministério da reforma psicológica [online]. Disponível em: $<$ https://www.youtube.com/watch?v=XReiV7NOH7M>. 2013. Acesso em 01 abril 2020.

CARVALHO, Olavo de. As armas da liberdade [online]. Disponível em: <http://olavodecarvalho.org/armas-da-liberdade/>. 2009. Acesso em 01 abril 2020.

Ideário do absurdo [online]. Disponível em: <http://olavodecarvalho.org/ideario-do-absurdo/>. 2000. Acesso em 01 abril 2020.

. O Imbecil Coletivo. $1^{\text {a }}$ edição. Rio de Janeiro: Record, 2018.

O Jardim das Aflições. $3^{\mathrm{a}}$ edição. Campinas, SP: Vide Editorial, 2015.

Perdendo o senso [online]. Disponível em: <http://olavodecarvalho.org/perdendo-o-senso/>. 2013. Acesso em 01 abril 2020.

CASTILHO, Jenifer. A verdade sobre o Escola sem Partido [online]. Disponível em: <https://www.institutoliberal.org.br/blog/verdade-sobre-o-escola-sem-partido/>. 2017. Acesso em 01 abril 2020.

CASTRO, Gabriel de Arruda. Cinco táticas de doutrinação em sala de aula que você precisa conhecer [online]. Disponível em: $<$ https://www.gazetadopovo.com.br/educacao/cinco-taticas-de-doutrinacao-em-sala-deaula-que-voce-precisa-conhecer-0bjj85rgqfajhagh43q0zi30v/>. 2017. Acesso em 01 abril 2020. 
COLOMBO, Luiza Rabelo. Reflexões sobre o movimento Escola sem Partido e seu avanço no campo das políticas educacionais brasileiras. Entropia, v. 2, n. 3, pp. 52-68, janeiro-junho 2018.

CONSTANTINO, Rodrigo. A revolução pedagógica como instrumento de doutrinação ideológica [online]. Disponível em: <https://www.gazetadopovo.com.br/rodrigo-constantino/historico-veja/a-revolucaopedagogica-como-instrumento-de-doutrinacao-ideologica/>. 2014. Acesso em 01 abril 2020 .

ESPINOSA, Betty R. Solano; QUEIROZ, Felipe B. Campanuci. Breve análise sobre as redes do Escola sem Partido. In: FRIGOTO, Gaudêncio (org.). Escola "sem" Partido: esfinge que ameaça a educação e a sociedade brasileira. Rio de Janeiro: UERJ, LPP, 2017, p. 49-62.

FREIRE, Paulo. Pedagogia da Autonomia. São Paulo: Paz e Terra, 2011.

FRIGOTO, Gaudêncio (org.). Escola "sem" Partido: esfinge que ameaça a educação e a sociedade brasileira. Rio de Janeiro: UERJ, LPP, 2017.

LACLAU, Ernesto. Emancipação e Diferença. Rio de Janeiro: EdUERJ, 2011.

LAGRAVE, CHARLES. O Império Ecológico e o totalitarismo planetário. apud CARVALHO, Olavo [online]. Disponível em: >http://olavodecarvalho.org/o-imperioecologico-e-o-totalitarismo-planetario/>. 1999. Acesso em 01 abril 2020.

MATTOS, Amana; MAGALDI, Ana Maria Bandeira de Mello; COSTA, Carina Martins; SILVA, Conceição Firmina Seixas; VELLOSO, Luciana; LEONARDI, Paula; ALBERTI, Verena; PENNA, Fernando de Araujo. Educação e liberdade: apontamentos para um bom combate ao projeto de lei Escola sem Partido. In: FRIGOTO, Gaudêncio (org.). Escola "sem" Partido: esfinge que ameaça a educação e a sociedade brasileira. Rio de Janeiro: UERJ, LPP, 2017, p. 87-104.

MIGUEL, Luis Felipe. Da "doutrinação marxista" à "ideologia de gênero" - Escola sem Partido e as leis da mordaça no parlamento brasileiro. Direito e Práxis. Rio de Janeiro, v. 07, n. 15, pp. 590-621, 2016.

MOUFFE, Chantal. Sobre o político. São Paulo: Martins Fontes, 2015.

MOURA, Fernanda Pereira de. "Escola sem Partido": Relações entre Estado, educação e religião e os impactos no ensino de história. 2016. 188p. Dissertação (Mestrado Profissional em Ensino de História) - Programa de Pós-Graduação em Ensino de História, Universidade Federal do Rio de Janeiro, Rio de Janeiro, 2016.

; SALLES, Diogo da Costa. O Escola sem Partido e o ódio aos professores que formam crianças (des)viadas. Periódicus: revista de estudos interdisciplinares em gêneros e sexualidades, v. 1, n. 9, pp. 136-160, maio-out. 2018. 
NAGIB, Miguel. Quem disse que educação sexual é conteúdo obrigatório? [online]. Disponível em: <http://escolasempartido.org/blog/quem-disse-que-educacao-sexual-econteudo-obrigatorio/>. 2013. Acesso em 01 abril 2020.

PENNA, Fernando de Araujo. O ódio aos professores. In: AÇÃO EDUCATIVA (org.). A ideologia do movimento Escola sem Partido: 20 autores desmontam o discurso. São Paulo: Ação Educativa, 2016b, p. 93-100.

Programa "Escola sem Partido": uma ameaça à educação emancipadora. In: GABRIEL, Carmen Teresa; MONTEIRO, Ana Maria; MARTINS, Marcus Leonardo Bomfim (orgs.). Narrativas do Rio de Janeiro nas aulas de história. Rio de Janeiro: Mauad X, 2016a, p. 43-58.

; SALLES, Diogo da Costa. A dupla certidão de nascimento do Escola sem Partido: analisando as referências intelectuais de uma retórica reacionária. In: MUNIZ, Altemar de Costa; LEAL, Tito Barros (orgs.) Arquivos, documentos e ensino de história: desafios contemporâneos. Fortaleza: EdUECE, 2017, p. 13-38.

RANCIÉRE, Jacques. O mestre ignorante: cinco lições sobre a emancipação intelectual. Belo Horizonte: Autêntica Editora, 2013.

SALLES, Diogo da Costa. Criando a doença para vender a cura: o discurso da "doutrinação ideológica" do Movimento Escola sem Partido. 2019. 147p. Dissertação (Mestrado em História Social). - Centro de Educação e Humanidades, Universidade do Estado do Rio de Janeiro, São Gonçalo, RJ, 2019.

SANTANA, Erivelton. Discurso em 16/03/2013 [online]. Disponível em: $<$ https://www.camara.leg.br/internet/sitaqweb/TextoHTML.asp?etapa $=5 \&$ nuSessao $=41$ 6.3.54. $\&$ \&uQuarto $=50 \&$ nuOrador $=2 \&$ nuInsercao $=0 \& d$ thorarioQuarto $=16: 27 \& \operatorname{sgFase}$ Sessao=GE\&Data $=16 / 12 / 2013 \&$ txApelido=ERIVELTON\%20SANTANA, \%20PSC BA\&txFaseSessao $=$ Grande $\% 20$ Expediente $\&$ txTipoSessao $=\mathrm{N} \% \mathrm{C} 3 \%$ A3o $\% 20$ Deliberati va\%20de\%20Debates\%20-\%20CD\&dtHoraQuarto=16:27\&txEtapa=>. 2013. Acesso em 01 abril 2020 